Published in final edited form as:

Ann N Y Acad Sci. 2011 August ; 1231(1): 17-22. doi:10.1111/j.1749-6632.2011.06028.x.

\title{
Social isolation
}

\author{
John T. Cacioppo ${ }^{1}$, Louise C. Hawkley ${ }^{1}$, Greg J. Norman ${ }^{1}$, and Gary G. Berntson ${ }^{2}$ \\ ${ }^{1}$ Center for Cognitive and Social Neuroscience, University of Chicago, Chicago, Illinois \\ ${ }^{2}$ Department of Psychology, Ohio State University, Columbus, Ohio
}

\section{Abstract}

Social species, by definition, form organizations that extend beyond the individual. These structures evolved hand in hand with behavioral, neural, hormonal, cellular, and genetic mechanisms to support them because the consequent social behaviors helped these organisms survive, reproduce, and care for offspring sufficiently long that they too reproduced. Social isolation represents a lens through which to investigate these behavioral, neural, hormonal, cellular, and genetic mechanisms. Evidence from human and nonhuman animal studies indicates that isolation heightens sensitivity to social threats (predator evasion) and motivates the renewal of social connections. The effects of perceived isolation in humans share much in common with the effects of experimental manipulations of isolation in nonhuman social species: increased tonic sympathetic tonus and HPA activation, and decreased inflammatory control, immunity, sleep salubrity, and expression of genes regulating glucocorticoid responses. Together, these effects contribute to higher rates of morbidity and mortality in older adults.

\section{Keywords}

social isolation; social neuroscience; loneliness; gene expression; health

\section{Introduction}

Social species, by definition, form organizations that extend beyond the individual. These structures evolved hand in hand with behavioral, neural, hormonal, cellular, and genetic mechanisms to support them because the consequent social behaviors helped these organisms survive, reproduce, and care for offspring sufficiently long that they too reproduced, thereby ensuring their genetic legacy. Social isolation represents a lens through which to investigate these behavioral, neural, hormonal, cellular, and genetic mechanisms.

Social isolation has significant effects. About a quarter century ago, House, Landis, and Umberson ${ }^{1}$ published a landmark review of prospective epidemiological studies of social isolation in humans. They reported that social isolation was a significant risk factor for broad-based morbidity and mortality—a finding that subsequent research has confirmed. ${ }^{2}$ What was especially surprising was that social isolation was as strong a risk factor for morbidity and mortality as smoking, obesity, sedentary lifestyle, and high blood pressure. ${ }^{1}$ The "social control hypothesis" was posited to explain the effect of isolation. Social control theory holds that internalized obligations to, and the overt influence of, network members tend to discourage poor health behaviors and encourage good health behaviors. ${ }^{3}$ For instance, among women, direct social control (i.e., "how often does anyone tell or remind

Correspondence: John T. Cacioppo, Center for Cognitive and Social Neuroscience, University of Chicago, 5848 S. University Avenue, Chicago, Illinois 60637. Cacioppo@uchicago.edu. 
you to do anything to protect your health?") predicted increased physical activity three years later. ${ }^{4}$ Being married is associated with an increased likelihood of engaging in healthpromoting behaviors such as exercise,${ }^{5-7}$ presumably because marital partners exert some influence over these behaviors. 8,9

There are two reasons, however, to regard the social control hypothesis as insufficient. First, studies of isolation and health behaviors indicate that social control does not explain many of the effects of isolation in humans. ${ }^{10,11}$ Second, experimental studies in nonhuman social species indicate that isolation has direct, deleterious physiological effects. For instance, experimental studies have documented that social isolation decreases the lifespan of the fruit fly, Drosophila melanogaster; ${ }^{12}$ increases infarct size and edema and decreases the poststroke survival rate following experimentally induced stroke in mice due to elevated levels of proinflammatorycytokines; ${ }^{13}$ increases obesity and Type 2 diabetes in mice; $;{ }^{14}$ delays the positive effects of running on adult neurogenesis in rats; ${ }^{15}$ increases the activation of the sympatho-adrenomedullary response to an acute immobilization or cold stressor in rats; ${ }^{16}$ decreases the expression of genes regulating glucocorticoid response in the frontal cortex of piglets; ${ }^{17}$ decreases open field activity, increases in basal cortisol concentrations, and decreases in lymphocyte proliferation to mitogens in pigs; ${ }^{18}$ increases the 24 hour urinary catecholamines levels and evidence of oxidative stress in the aortic arch of the Watanabe heritable hyperlipidemic rabbit; ${ }^{19}$ and increases the morning rises in cortisol in squirrel monkeys. ${ }^{20}$ Together, these experimental studies suggest that social isolation increases chronic sympathetic tonus, oxidative stress, and HPA activation while decreasing inflammatory control, immunity, and the expression of genes regulating glucocorticoid responses.

\section{Social isolation in humans}

In ontogeny and phylogeny, humans need others to survive and prosper. Animal studies of social isolation are an important complement to human studies because randomization and experimental manipulations of isolation in humans are limited in intensity and duration by the possible damaging effects. In addition, longitudinal studies of social isolation in population-based samples with statistical controls for potential confounding variables (e.g., negativity, depressive symptomatology) have begun to identify potential behavioral, neural, hormonal, cellular, and genetic effects of isolation in humans. ${ }^{21,22}$ Among the findings in this research are that: (1) perceived social isolation is a more important determinant of deleterious outcomes than is the variation in objective social isolation that is seen in population based studies; and (2) the effects of perceived isolation in these longitudinal studies share much in common with the effects of experimental manipulations of isolation in nonhuman social species: increased tonic sympathetic tonus and HPA activation and decreased inflammatory control and immunity; expression of genes regulating glucocorticoid responses; and glucocorticoid resistance.

Humans predate one another, and humans are capable of deception, betrayal, exploitation, and murder as well as empathy, compassion, loyalty, and prosocial behavior. Given shifting alliances and malleable social hierarchies, the presence of others, even ostensive friends, may constitute a social threat at any moment in time. The objective presence of others, therefore, is not sufficient to ensure the social connections needed for human survival and prosperity. Fortunately, assessments have been developed with which to measure perceived as well as objective isolation. Studies using these assessments indicate that objective social isolation can affect perceptions of isolation, ${ }^{23,24}$ but show that perceived social isolation is more closely related to the quality than the quantity of social interactions. ${ }^{25}$ 
When the effects of each are contrasted, perceived social isolation predicts various outcomes above and beyond what is predicted by objective isolation. Beyond what is predicted by objective isolation, perceived isolation predicts greater vascular resistance, ${ }^{26}$ elevated blood pressure, ${ }^{27,28}$ morning rise in cortisol, ${ }^{29}$ less salubrious sleep, ${ }^{28,30}$ and sedentary lifestyles. ${ }^{31}$ Perceived (but not objective) social isolation has also been associated with gene expression - specifically, the under-expression of genes bearing anti-inflammatory glucocorticoid response elements and over-expression of genes bearing response elements for proinflammatory NK- $\mathrm{kB} /$ Rel transcription factors. ${ }^{32}$ This finding is paralleled by decreases in lymphocyte sensitivity to physiological regulation by the hypothalamic pituitary adrenocortical (HPA) axis in individuals who feel socially isolated. ${ }^{33}$ Together with evidence of increased activity of the HPA axis, ${ }^{29,34}$ these results suggest the development of glucocorticoid resistance in individuals who feel chronically isolated.

In a longitudinal study of cognitive functioning, Wilson et al. ${ }^{35}$ reported that perceived social isolation predicted cognitive decline and risk for Alzheimer's disease (AD). Importantly, perceived isolation persisted in predicting each of these outcomes even when social network size and frequency of social activity were statistically held constant. Similarly, perceived isolation has been found to predict lifetime change in $\mathrm{IQ}^{36}$ and changes in depressive symptoms $\mathrm{s}^{37,38}$ beyond what could be predicted by objective isolation. Experimental manipulation of social isolation ${ }^{39}$ and imagined future isolation ${ }^{40}$ result in cognitive and behavioral changes even though objective isolation is not altered in these experimental studies. An experience sampling study, in which participants were beeped randomly nine times per day for seven days, confirmed that the social interactions of individuals who feel isolated, in contrast to connected, were more negative and less satisfying, and such interactions contributed subsequently to more negative moods and interactions. $^{41}$

Perceived social isolation, known more colloquially as loneliness, was characterized in early scientific investigations as "a chronic distress without redeeming features". ${ }^{42}$ Recent research suggests that the social pain of loneliness evolved as a signal that one's connections to others are weakening and to motivate the repair and maintenance of the connections to others that are needed for our health and well-being and for the survival of our genes. ${ }^{43}$ Physical pain is an aversive signal that evolved to motivate one to take action to minimize damage to one's body. Feeling socially disconnected and isolated triggers social pain, an aversive signal that evolved to motivate one to take action that minimizes threats or damage to one's social body. Research on social rejection, for instance, suggests that social pain coopted the physical pain to extend its protective function to include those with whom we form connections. In Eisenberger, Lieberman, and Williams, ${ }^{44}$ participants were excluded from or included in a social situation (i.e., a ball tossing game). Results revealed neural activation localized in a dorsal portion of the anterior cingulate cortex (dACC) that is implicated in the affective component of the physical pain response. Eisenberger and her colleagues suggest that, "Because of the adaptive value of mammalian social bonds, the social attachment system... may have piggybacked onto the physical pain system to promote survival" (p. 291).

Open field behavior in nonhuman animals represents a compromise between predator evasion tactics and the reinstatement of contact with an ingroup. ${ }^{45,46}$ Evidence from behavioral and fMRI studies suggest that social isolation increases attention to negative social stimuli (e.g., social threats) as well as increased motivation to reconnect. Using a modified emotional Stroop task, individuals who felt isolated, relative to those who felt connected, showed greater Stroop interference, specifically for negative social relative to negative non-social words. ${ }^{47}$ No differences were found in Stroop interference for positive social relative to positive non-social words. Stroop interference is used to gauge the implicit 
processing of stimuli, so these results suggest that perceived isolation is associated with a heightened accessibility of negative social information. Similarly, Yamada and Decety ${ }^{48}$ investigated the effects of subliminal priming on the detection of painful facial expressions. Using signal detection analyses, they found that although the pain was more easily detected in dislikable than likable faces overall, lonely individuals were more sensitive (d') to the presence of pain in dislikable faces than were nonlonely individuals.

In an fMRI study, we found that individual differences in perceived isolation predicted the activation of the visual cortex to the presentation of unpleasant social, in contrast to nonsocial, pictures, consistent with the remnants of greater predator evasion and a stronger focus on self-preservation in individuals who feel isolated. To examine this possibility, activation in the temporoparietal junction (TPJ) — a region that has been found previously to be activated in theory of mind tasks and in tasks in which individuals take the perspective of another-was also examined. ${ }^{47}$ TPJ activation was observed when participants viewed unpleasant pictures of people versus objects and, as would be expected if isolation increases a focus on predator evasion and self-preservation, individual differences in perceived social isolation were inversely related to the amount of activation observed in the TPJ.

We also investigated the extent to which individual differences in perceived isolation predicted differential activation of the ventral striatum to pleasant social versus matched nonsocial images. ${ }^{47}$ The ventral striatum, a key component of the mesolimbic dopamine system, is rich in dopaminergic neurons and is critical in reward processing and learning. ${ }^{49,50}$ The ventral striatum is activated by primary rewards such as stimulant drugs, ${ }^{51}$ abstinence-induced cravings for primary rewards, ${ }^{52}$ and secondary rewards such as money. ${ }^{53}$ Evidence that social rewards also activate the ventral striatum has begun to accumulate in studies of romantic love, ${ }^{54}$ social cooperation, ${ }^{55}$ social comparison, ${ }^{56}$ and punitive altruism. ${ }^{57} \mathrm{We}$ found that perceived isolation predicted weaker activation of the ventral striatum to pleasant pictures of people than of equally pleasant pictures of objects. These results raise several interesting questions. As noted above, an experience sampling study indicated that individuals who felt socially isolated regard pleasant interpersonal interactions as less pleasant than do individuals who feel socially connected. ${ }^{41}$ Does perceived isolation modulate the responsiveness of rudimentary reward systems to social and nonsocial stimuli, or do preexisting differences in dopaminergic response to appetitive social and nonsocial stimuli lead to differences in social isolation? Although animal studies may be particularly informative, the finding that individual differences in perceived social isolation are about $50 \%$ heritable increases the plausibility of the latter hypothesis.

\section{Heritability}

That perceived isolation has an evolutionary basis is suggested by adoption and twin studies with children ${ }^{58,59}$ and with adults. ${ }^{60-62}$ These studies indicate that the heritability of individual differences in perceived isolation is approximately $50 \%$. We have interpreted this heritability as reflecting differences in sensitivity to the pain of social disconnection. ${ }^{63}$ But what evidence is there that this heritability reflects, at least in part, individual differences in sensitivity to social disconnection? Myron Hofer's ${ }^{45}$ research on the selective breeding of rats provides a provocative case. A well-characterized response to maternal separation is the separation cry. In the rat, the separation cry is in the ultrasonic range $(40-45 \mathrm{kHz})$. These ultrasonic vocalizations (USVs) to isolation are attenuated in a dose-related fashion by anxiolytics that act on benzodiazepine and serotonin receptors and are exaggerated by anxiogenics such as the benzodiazepine receptor partial inverse agonist FG7142. ${ }^{64}$ Neuroanatomical studies reviewed by $\mathrm{Hofer}^{45}$ point to the periaquaductal grey area as a neural substrate for these USVs in rats and the hypothalamus, amygdala, thalamus, 
hippocampus, and cingulate cortex as the neural substrates for isolation calls in primates. As Hofer notes:

The evolution of such a response is clarified by the finding that infant rat USV is a powerful stimulus for the lactating rat, capable of causing her to interrupt an ongoing nursing bout, initiate searching outside the nest, and direct her search toward the source of the calls...The mother's retrieval response to the pup's vocal signals then results in renewed contact between pup and mother. This contact, in turn, quiets the pup. ${ }^{45}$

Hofer uses the concept of attachment to describe the emotional expression represented by the USVs and the reestablishment of the social bond by the maternal search for, renewed contact with, and comfort response of the rat pup.

Although the infant USV helps guide the mother to the infant, these USVs can also lead predators to the infant. USVs may be beneficial or deleterious depending on the presence of predators in the environment. As a consequence, no single level of intensity of USVs to isolation is universally best, and heritable individual differences in this predisposition exist in the population. Some rat pups, who might be characterized as sensitive to separation, cry frequently (albeit ultrasonically) when isolated, whereas others are less sensitive to separation and show less distress when isolated. Hofer and colleagues selectively bred adult rats that, as rat pups, showed either high or relatively low rates of USVs to separation. ${ }^{65}$ After 25 generations of selective breeding, differences in behavior between the two lines of rats were reminiscent of some of the differences observed in humans who are high or low in perceived isolation: ${ }^{22}$ the high, relative to low, USV line showed more distress to isolation as an infant; greater latency to play as an adolescent; and greater depression-like behaviors, greater anxiety-like behaviors, greater latency to social interactions, greater startle, and diminished learning as an adult. That is, the high USV line was anxious and passive, whereas the low USV line was exploratory, active, and aggressive. ${ }^{45}$ This work, then, suggests a link between individual differences in perceived social isolation and attachment processes and points to a specific aspect of the phenotype (sensitivity to isolation) and an evolutionary mechanism for this phenotype. Note, however, that in this context the motherinfant attachment builds on heritable differences in sensitivity to isolation rather than the pain of isolation resulting from poor infant attachment behaviors by the mother. Moreover, perceived isolation in humans represents a complex phenotype, so attachment may not represent its sole evolutionary basis.

\section{Summary}

Experimental, cross-sectional, and longitudinal studies are beginning to elucidate the various ways in which perceived isolation is related to, and in some cases affects, human neural, hormonal, cellular, and genetic processes. Early in our history as a species, we survived and prospered only by banding together-in couples, in families, in tribes- to provide mutual protection and assistance. The pain of (perceived) isolation evolved like any other form of pain. Indeed, there is now considerable evidence that social isolation, and the pain associated with the disconnection that produces isolation, can fruitfully be conceived as a biological construct, a state that has evolved as an aversive signal that motivates changes behavior to help individuals avoid damage and promote the transmission of genes to the gene pool. In the case of isolation, the signal is a prompt to be alert to social threats (predator evasion) and to renew the connections we need to survive and prosper. The effects of perceived isolation in humans share much in common with the effects of experimental manipulations of isolation in nonhuman social species: increased tonic sympathetic tonus and HPA activation, glucocorticoid resistance, decreased inflammatory control, immunity, sleep salubrity, and expression of genes regulating glucocorticoid responses. The 
combination of immunosuppression and pro-inflammatory effects may be especially caustic.

Together, these effects contribute to higher rates of morbidity and mortality in older adults.

\section{Acknowledgments}

This research was supported by National Institute of Aging Grant No. RO1 AG034052-01.

\section{References}

1. House JS, Landis KR, Umberson D. Social relationships and health. Science (New York, N.Y.). 1988; 241:540-545.

2. Holt-Lunstad J, Smith TB, Layton JB. Social Relationships and Mortality Risk: A Meta-analytic Review. PLoS Medicine. 2010; 7:e1000316. [PubMed: 20668659]

3. Umberson D. Family Status and Health Behaviors: Social Control as a Dimension of Social Integration. Journal of Health and Social Behavior. 1987; 28:306-319. [PubMed: 3680922]

4. Umberson D. Gender, marital status and the social control of health behavior. Social Science \& Medicine. 1992; 34:907-917. [PubMed: 1604380]

5. Pettee K, et al. Influence of Marital Status on Physical Activity Levels among Older Adults. MEDICINE AND SCIENCE IN SPORTS AND EXERCISE. 2006; 38:541-546. [PubMed: 16540843]

6. Satariano W. Living Arrangements and Participation in Leisure-Time Physical Activities in an Older Population. Journal of Aging and Health. 2002; 14:427-451. [PubMed: 12391994]

7. Schmitz K. Correlates of Changes in Leisure Time Physical Activity over 2 Years: The Healthy Worker Project. Preventive Medicine. 1997; 26

8. Umberson D. Family Status and Health Behaviors: Social Control as a Dimension of Social Integration. Journal of Health and Social Behavior. 1987; 28

9. Umberson D. Gender, marital status and the social control of health behavior. Social science \& medicine (1982). 1992; 34

10. Hawkley LC, Thisted R, Cacioppo JT. Loneliness predicts reduced physical activity: crosssectional \& longitudinal analyses. Health psychology : official journal of the Division of Health Psychology, American Psychological Association. 2009; 28:354-363.

11. Seeman TE. Health promoting effects of friends and family on health outcomes in older adults. American Journal of Health Promotion. 2000; 14:362-370. [PubMed: 11067571]

12. Ruan H, Wu C-F. Social interaction-mediated lifespan extension of Drosophila Cu/Zn superoxide dismutase mutants. Proceedings of the National Academy of Sciences of the United States of America. 2008; 105:7506-7510. [PubMed: 18508973]

13. Karelina K, et al. Estrous phase alters social behavior in a polygynous but not a monogamous Peromyscus species. Hormones and behavior. 2010; 58:193-199. [PubMed: 20382149]

14. Nonogaki K, Nozue K, Oka Y. Social isolation affects the development of obesity and type 2 diabetes in mice. Endocrinology. 2007; 148:4658-4666. [PubMed: 17640995]

15. Stranahan AM, Khalil D, Gould E. Social isolation delays the positive effects of running on adult neurogenesis. Nature neuroscience. 2006; 9:526-533.

16. Dronjak $\mathrm{S}$, et al. Immobilization and cold stress affect sympatho-adrenomedullary system and pituitary-adrenocortical axis of rats exposed to long-term isolation and crowding. Physiology and Behavior. 2004; 81:409-415. [PubMed: 15135012]

17. Poletto R, et al. Effects of early weaning and social isolation on the expression of glucocorticoid and mineralocorticoid receptor and 11beta-hydroxysteroid dehydrogenase 1 and 2 mRNAs in the frontal cortex and hippocampus of piglets. Brain research. 2006; 1067:36-42. [PubMed: 16271354]

18. Kanitz E, et al. Consequences of repeated early isolation in domestic piglets (Susscrofa) on their behavioural, neuroendocrine, and immunological responses. Brain, Behavior, and Immunity. 2004; $18: 35-45$. 
19. Nation DA, et al. The effect of social environment on markers of vascular oxidative stress and inflammation in the Watanabe heritable hyperlipidemic rabbit. Psychosomatic medicine. 2008; 70:269-275. [PubMed: 18256340]

20. Lyons D, Ha C, Levine S. Social effects and circadian rhythms in squirrel monkey pituitaryadrenal activity. Hormones and Behavior. 1995; 29:177-190. [PubMed: 7557921]

21. Cacioppo JT, et al. Loneliness as a specific risk factor for depressive symptoms: cross-sectional and longitudinal analyses. Psychology and aging. 2006; 21:140-151. [PubMed: 16594799]

22. Cacioppo JT, Hawkley LC. Perceived social isolation and cognition. Trends in cognitive sciences. 2009; 13:447-454. [PubMed: 19726219]

23. Hawkley LC, et al. From social structure factors to perceptions of relationship quality and loneliness: The Chicago Health, Aging, and Social Relations Study. Journal of Gerontology: Social Sciences. 2008; 63B:S375-S384.

24. Ruiz J. Emotional Climate in Organizations: Applications in Latin American Prisons. Journal of Social Issues. 2007; 63:289-306.

25. Hawkley LC, et al. From social structural factors to perceptions of relationship quality and loneliness: the Chicago health, aging, and social relations study. The journals of gerontology. Series B, Psychological sciences and social sciences. 2008; 63:S375-S384.

26. Cacioppo JT, et al. Loneliness and Health : Potential Mechanisms. Psychosomatic Medicine. 2002; 64:407-417. [PubMed: 12021415]

27. Hawkley LC, et al. Loneliness is a unique predictor of age-related differences in systolic blood pressure. Psychology and Aging. 2006; 21:152-164. [PubMed: 16594800]

28. Hawkley LC, Preacher KJ, Cacioppo JT. Loneliness impairs daytime functioning but not sleep duration. Health psychology : official journal of the Division of Health Psychology, American Psychological Association. 2010; 29:124-129.

29. Adam EK, et al. Day-to-day dynamics of experience--cortisol associations in a population-based sample of older adults. Proceedings of the National Academy of Sciences of the United States of America. 2006; 103:17058-17063. [PubMed: 17075058]

30. Cacioppo JT, et al. Do lonely days invade the nights? Potential social modulation of sleep efficiency. Psychological science : a journal of the American Psychological Society / APS. 2002; 13:384-387.

31. Hawkley LC, Thisted RA, Cacioppo JT. Loneliness predicts reduced physical activity: crosssectional \& longitudinal analyses. Health psychology : official journal of the Division of Health Psychology, American Psychological Association. 2009; 28:354-363.

32. Cole SW, et al. Social regulation of gene expression in human leukocytes. Genome biology. 2007; 8:R189. [PubMed: 17854483]

33. Cole SW. Social regulation of leukocyte homeostasis: the role of glucocorticoid sensitivity. Brain, behavior, and immunity. 2008; 22:1049-1055.

34. Steptoe A, et al. Loneliness and neuroendocrine, cardiovascular, and inflammatory stress responses in middle-aged men and women. Psychoneuroendocrinology. 2004; 29:593-611. [PubMed: 15041083]

35. Wilson RS, et al. Loneliness and risk of Alzheimer disease. Archives of general psychiatry. 2007; 64:234-240. [PubMed: 17283291]

36. Gow AJ, et al. Social support and successful aging: Investigating the relationship between lifetime cognitive change and life satisfaction. Journal of Individual Differences. 2007; 28:103-115.

37. Cacioppo JT, et al. Loneliness as a specific risk factor for depressive symptoms: cross-sectional and longitudinal analyses. Psychology and aging. 2006; 21:140-151. [PubMed: 16594799]

38. Cacioppo JT, Hawkley LC, Thisted RA. Perceived social isolation makes me sad: 5-year crosslagged analyses of loneliness and depressive symptomatology in the Chicago Health, Aging, and Social Relations Study. Psychology and aging. 2010; 25:453-463. [PubMed: 20545429]

39. Cacioppo JT, et al. Loneliness within a nomological net: An evolutionary perspective. Journal of Research in Personality. 2006; 40:1054-1085.

40. Baumeister RF, Twenge JM, Nuss CK. Effects of social exclusion on cognitive processes: anticipated aloneness reduces intelligent thought. Journal of personality and social psychology. 2002; 83:817-827. [PubMed: 12374437] 
41. Hawkley LC, Preacher KJ, Cacioppo JT. Multilevel modeling of social interactions and mood in lonely and social connected individuals: the MacArthur Social Neuroscience Studies. Oxford Handbook of Methods in Positive Psychology. 2007:559-575.

42. Weiss, R. Loneliness: the experience of emotional and social isolation. Cambridge Mass: MIT Press; 1974. at <http://www.worldcat.org/title/loneliness-the-experience-of-emotional-and-social-isolation/oclc/ 659037\&referer=brief_results $>$

43. Cacioppo, JT.; Patrick, B. Loneliness: Human nature and the need for social connection. New York: W. W. Norton \& Company; 2008.

44. Eisenberger NI, Lieberman MD, Williams KD. Does rejection hurt? An FMRI study of social exclusion. Science (New York, N.Y.). 2003; 302:290-292.

45. Hofer MA. Developmental neuroscience. Handbook of Neuroscience for the Behavioral Sciences. 2009:12-31.

46. Suarez SD, Gallup GG. An ethological analysis of open-field behavior in rats and mice. Learning and Motivation. 1981; 12:342-363.

47. Cacioppo JT, et al. In the eye of the beholder: individual differences in perceived social isolation predict regional brain activation to social stimuli. Journal of cognitive neuroscience. 2009; 21:8392. [PubMed: 18476760]

48. Yamada M, Decety J. Unconscious affective processing and empathy: an investigation of subliminal priming on the detection of painful facial expressions. Pain. 2009; 143:71-75. [PubMed: 19254825]

49. Delgado MR, Frank RH, Phelps E. Perceptions of moral character modulate the neural systems of reward during the trust game. Nature neuroscience. 2005; 8:1611-1618.

50. O'Doherty JP. Reward representations and reward-related learning in the human brain: Insights from neuroimaging. Current opinion in neurobiology. 2004; 14:769-776. [PubMed: 15582382]

51. Leyton M. Conditioned and sensitized responses to stimulant drugs in humans. Progress in neuropsychopharmacology \& biological psychiatry. 2007; 31:1601-1613. [PubMed: 17888557]

52. Wang Z, et al. Neural Substrates of Abstinence-Induced Cigarette Cravings in Chronic Smokers. The journal of neuroscience : the official journal of the Society for Neuroscience. 2007; 27:1403514040. [PubMed: 18094242]

53. Seymour B, et al. Differential Encoding of Losses and Gains in the Human Striatum. The journal of neuroscience : the official journal of the Society for Neuroscience. $2007 ; 27: 4826-4831$. [PubMed: 17475790]

54. Aron A, et al. Reward, motivation, and emotion systems associated with early-stage intense romantic love. Journal of Neurophysiology. 2005; 94:327. [PubMed: 15928068]

55. Rilling J, et al. A neural basis for social cooperation. Neuron. 2002; 35:395-405. [PubMed: 12160756]

56. Fliessbach K, et al. Social Comparison Affects Reward-Related Brain Activity in the Human Ventral Striatum. Science. 2007; 318:1305-1308. [PubMed: 18033886]

57. Quervain, DJ-F de, et al. The neural basis of altruistic punishment. Science (New York, N.Y.). 2004; 305:1254-1258.

58. Bartels M, et al. Genetic and environmental contributions to stability in loneliness throughout childhood. American journal of medical genetics. Part B, Neuropsychiatric genetics : the official publication of the International Society of Psychiatric Genetics. 2008; 147:385-391.

59. McGuire S, Clifford J. Genetic and environmental contributions to loneliness in children. Psychological science : a journal of the American Psychological Society / APS. 2000; 11:487-491.

60. Boomsma DI, et al. Longitudinal genetic analysis for loneliness in Dutch twins. Twin research and human genetics : the official journal of the International Society for Twin Studies. 2007; 10:267273. [PubMed: 17564516]

61. Boomsma DI, et al. Genetic and environmental contributions to loneliness in adults: the Netherlands twin register study. Behavior genetics. 2005; 35:745-752. [PubMed: 16273322]

62. Boomsma D. Genetic Linkage and Association Analysis for Loneliness in Dutch Twin and Sibling Pairs Points to a Region on Chromosome 12q23-24. Behavior Genetics. 2006; 36:137-146. [PubMed: 16378171] 
63. Cacioppoq JT, Hawkley LC, Correll J. Perceived social isolation within personal and evolutionary timescales. Handbook of Social Exclusion. in press.

64. Brunelli SA, Hofer MA. Selective breeding for an infantile phenotype (isolation calling): A window on development processes. Handbook of Behavioral Neurobiology. 2001:433-482.

65. Brunelli S, Hofer MA. Selective breeding for infant rat separation-induced ultrasonic vocalizations: Developmental precursors of passive and active coping styles. Behavioural brain research. 2007; 182:193. [PubMed: 17543397] 